\title{
PROCEEDINGS
}

OF THE

\section{羽ebistorit Soctety}

OF

\section{EAST ANGLIA}

For 1923-24.

VOL IV.-PART 11.

(Edited by G. MAYNARD, F.R.A.I., Hon. Secretary.

\author{
$=$ \\ W. E. HARRISON, \\ THE ANCIENT HOUSE, IPSWICH. \\ 1924. \\ London Agents : \\ H. K. LEWIS \& Co., LTw., \\ 136, Gower Street, W.C.1.
}

